\title{
Effects of Epicardial Fat Reduction on P-wave Duration of Morbidly Obese Patients Submitted to Bariatric Surgery: an Observational Study
}

\author{
Efeitos da Redução da Gordura Epicárdica na Duração da Onda P de Obesos \\ Mórbidos Submetidos à Cirurgia Bariátrica: um Estudo Observacional \\ Acácio Fernandes-Cardoso ${ }^{1, *}$, Meive Santos-Furtado², José Grindler ${ }^{1}$, Alfredo José Fonseca1,
Carlos Rodrigues Oliveira1, Nemer Luiz Pichara ${ }^{1}$, Roberto Cleva ${ }^{3}$, Marco Aurélio Santo ${ }^{3}$
}

ORCID IDS

$\begin{array}{ll}\text { Cardoso AF (D) https://orcid.org/0000-0002-4613-4181 } & \text { Oliveira CR (D) https://orcid.org/0000-0003-1971-5156 } \\ \text { Furtado MS (D) https://orcid.org/0000-0002-9051-0877 } & \text { Pichara NL (D) https://orcid.org/0000-0001-7175-3593 } \\ \text { GrindlerJ (D) https://orcid.org/0000-0001-6646-6469 } & \text { Cleva R (D) https://orcid.org/0000-0001-8673-9014 } \\ \text { Fonseca AJ (D) https://orcid.org/0000-0001-8632-5428 } & \text { Santo MA (D) https://orcid.org/0000-0002-7813-6210 }\end{array}$

\begin{abstract}
Introduction: Epicardial fat (EF) is biologically active and, through its paracrine effect, interacts with the atrial myocardium and may be involved in the atrial remodeling observed in obese individuals. P-wave duration (PWD) is a non-invasive marker of atrial conduction time and reflects changes related to atrial remodeling. The effects of the reduction of EF induced by bariatric surgery on PWD have not yet been defined. Methods: We prospectively recruited 22 morbidly obese patients with no other comorbidities at the Unidade de Cirurgia Bariátrica (Bariatric Surgery Unit) of Unviversidade de São Paulo's Hospital das Clínicas. The patients were submitted to clinical and laboratorial evaluations, 12-lead eletrocardiography (ECG), two-dimensional echocardiogram and $24 \mathrm{~h}$ Holter. The same evaluation was performed 12 months after bariatric surgery. In order to make a comparison of the continuous variables, we used the paired and Wilcoxon T tests. To evaluate the association between independent variables, a regression model was used for repeated measures. Results: A total of 20 patients completed the protocol (age: $36.35 \pm 10.26$ years, 18 women). There was a significant reduction of PWD, body mass index $(\mathrm{BMI})$ and $\mathrm{EF}$ after bariatric surgery $(\mathrm{p}<0.05)$. There was also an average reduction of $11.55 \pm 8.49$ ms in PWD. In the multiple regression analysis, an association was observed between the reduction of PWD and the reduction of EF and BMI. Conclusions: In morbidly obese patients with no other comorbidities, the reduction of EF after bariatric surgery was associated with an improvement in atrial remodeling indicated by a significant reduction in PWD.
\end{abstract}

KEYWORDS: P wave; Morbid obesity; Bariatric surgery.

\section{RESUMO}

Introdução: A gordura epicárdica (GE) é biologicamente ativa e, por meio de seu efeito parácrino, interage com o miocárdio atrial e pode estar envolvida no remodelamento atrial observado em obesos. A duração da onda P (DOP) é um marcador não invasivo do tempo de condução atrial e reflete alterações relacionadas ao remodelamento atrial. Os efeitos da redução da GE induzida pela cirurgia bariátrica sobre a DOP ainda não foram definidos. Métodos: Recrutamos prospectivamente 22 obesos mórbidos sem outras comorbidades na Unidade de Cirurgia Bariátrica do Hospital das Clínicas da Universidade de São Paulo. Os pacientes foram submetidos a avaliações clínica e laboratorial, além de eletrocardiograma (ECG) de 12 derivações, ecocardiograma bidimensional e Holter de $24 \mathrm{~h}$. A mesma avaliação foi realizada 12 meses após a cirurgia bariátrica. A fim de que as variáveis contínuas fossem comparadas, foram utilizados os testes T pareado e de Wilcoxon. Já para avaliar a associação entre variáveis independentes foi utilizado um modelo de regressão para medidas repetidas. Resultados: Ao todo, 20 pacientes completaram o protocolo (idade: $36,35 \pm 10,26$ anos, 18 mulheres). Houve uma redução significativa da DOP, do índice de massa corporal (IMC) e da GE após cirurgia bariátrica $(p<0,05)$. Houve também redução média de 11,55 \pm 8,49 ms na DOP. Na análise de regressão múltipla, foi observada associação entre a redução da DOP e a redução da GE e do IMC. Conclusões: Em obesos mórbidos sem outras comorbidades, a redução da GE após cirurgia bariátrica foi associada a melhora do remodelamento atrial, indicada por uma redução significativa da DOP.

PALAVRAS-CHAVE: Onda P; Obesidade mórbida; Cirurgia bariátrica.

1.Universidade de São Paulo - Faculdade de Medicina - Departamento de Clínica Médica - São Paulo/SP - Brazil.

2.Universidade de São Paulo - Faculdade de Medicina - Instituto de Radiologia -São Paulo/SP - Brazil.

3. Universidade de São Paulo - Faculdade de Medicina - Departamento de Gastroenterologia - São Paulo/SP - Brazil.

*Correspondence author: acacio.cardoso@hc.fm.usp.br

Received: 18 Jul 2019 | Accepted: 14 Ago 2019

Section Editor: José Tarcísio Medeiros de Vasconcelos 


\section{INTRODUCTION}

Epicardial fat $(\mathrm{EF})$ is a layer of adipose tissue located between the surface of the myocardium and the visceral pericardium. It covers $80 \%$ of the cardiac surface and is responsible for $20 \%$ of total heart weight. EF is mainly found in the atrioventricular and interventricular sulci, around the atria and along the coronary arteries ${ }^{1,2}$. Under normal physiological conditions, it performs a cardioprotective function by releasing energy to the myocardium in situations of high metabolic demand. Also, it participates in thermoregulation, acts as a protection for ganglia and nerves and in the regulation of vasomotricity of the coronary circulation ${ }^{3}$.

The thickness and volume of EF in obese individuals are recognizably greater ${ }^{4}$. Excess of $\mathrm{EF}$ in this population has been associated with the pathophysiology of some cardiovascular diseases, such as metabolic syndrome, coronary artery disease, and atrial fibrillation ${ }^{5-7}$. Since it is biologically active and presents ample interaction with the atrial myocardium, it is speculated that EF could produce a series of pro-inflammatory mediators capable of inducing the triggering of atrial fibrosis in obese individuals ${ }^{8}$. The duration of the $\mathrm{P}$ wave in electrocardiograms (ECG) is admittedly a marker of atrial remodeling and is associated with a higher risk of atrial fibrillation ${ }^{9}$. Recently, our group demonstrated that, in morbidly obese individuals, EF thickness was independently associated with a longer duration of the $\mathrm{P}$ wave, reinforcing the negative impact of $\mathrm{EF}$ on atrial remodeling ${ }^{10}$. The objective of the present study was to evaluate the effects of the reduction of $\mathrm{EF}$ on the $\mathrm{P}$ wave duration after weight loss induced by bariatric surgery.

\section{METHODS Population of the Study}

Between March 2015 and February 2016, we consecutively recruited 22 morbidly obese patients at the Bariatric Surgery Unit of the Clinical Hospital of the University of São Paulo Medical School (HCFMUSP). In the week before bariatric surgery, the participants underwent anthropometric evaluation, clinical history, physical examination, laboratory tests, as well as 12-lead ECG, 24-hour Holter, and two-dimensional echocardiogram.
The same evaluation, except for the 24-hour Holter, was repeated 12 months after the bariatric surgery. Patients with arterial hypertension, diabetes, dyslipidemia, presence of heart disease, branch blocks, history of fibrillation or atrial flutter, presence of significant arrhythmias in the 24-h Holter, anemia or thyroid dysfunction, and those who did not complete the evaluation protocol were excluded from the sample (Fig. 1). The ethics committee approved the study protocol, and all participants signed the informed consent form.

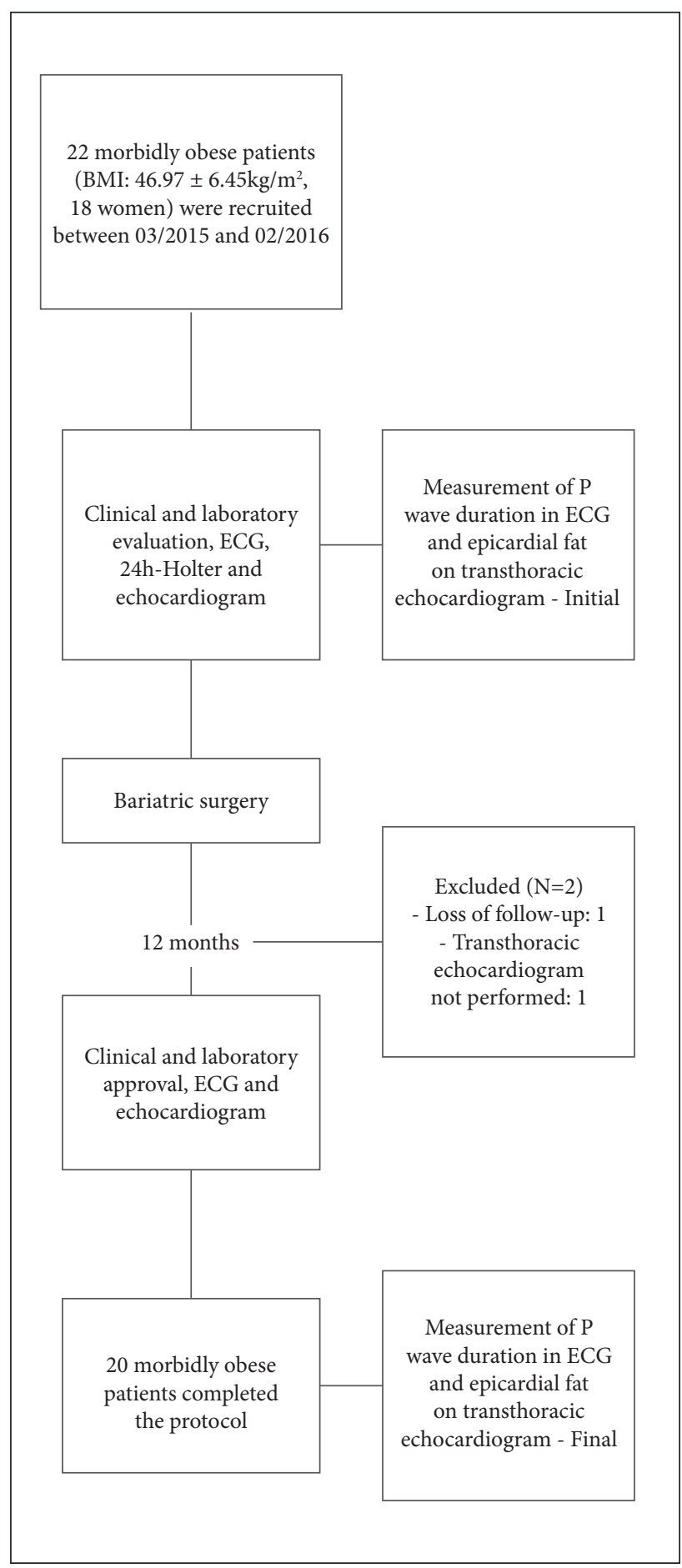

Figure 1. Study flowchart. 


\section{Echocardiogram Analysis}

A two-dimensional echocardiogram (Artida ${ }^{\circledR}$, Toshiba Medical Systems) was performed at rest by the same observer using a PST-25BT 1.8-4.2 MHz transducer in the preoperative period and 12 months after bariatric surgery. With the patients in left lateral decubitus position, through the parasternal long- and short-axes, and apical two- and four-chamber views, the following parameters were accessed: left atrial diameter, systolic and diastolic diameters of the left ventricle (LV), right ventricular cavity diameter, and thickness of the interventricular septum and the LV posterior wall. The LV ejection fraction was estimated by the Teichholz biplane method. To evaluate the diastolic function, the mitral flow velocities by pulsed Doppler were taken into consideration to determine the $\mathrm{E}$ and $\mathrm{A}$ waves. The $\mathrm{E} / \mathrm{A}$ ratio was used to evaluate the diastolic function. Devereux's formula calculated the LV mass.

\section{Evaluation of Epicardial Fat}

The EF thickness was defined according to the method previously described and validated11. EF was obtained during three consecutive cardiac cycles in longitudinal and transversal parasternal views in the right ventricular (RV) free wall during the end of systole, using the interventricular septum and the aortic ring as anatomical references. The space between the myocardial surface and the visceral pericardium was considered EF. The mean of the measurements recorded in the two incidences was considered the final result of the EF thickness. To evaluate the reproducibility of the method, the images were transferred to a workstation, where a second observer, blind to the patients' clinical condition, reassessed the measurement of EF. Considering the total number of measurements performed pre- and postoperatively, $50 \%$ of the sample was randomly selected to perform the interobserver analysis. A good correlation between observers was demonstrated $(\mathrm{g}=0.9$; CI 95\% [0.8 - 1.0]).

\section{Evaluation of P Wave Duration In ECG}

A 12-lead ECG with simultaneous recording was performed in the pattern $2 N$ (recording speed of $50 \mathrm{~mm} / \mathrm{s}$ and amplitude of $2 \mathrm{mV} / \mathrm{cm}$ ) in all participants. All ECGs were obtained in the same device and in the same period (between 10 am and $12 \mathrm{pm}$ ) to avoid circadian variations of electrocardiographic intervals. The examination was repeated under the same conditions 12 months after bariatric surgery. The $\mathrm{P}$ wave duration analysis was performed by a single observer with experience in the method and blind to the clinical condition of the participants. At least nine leads in which the $\mathrm{P}$ wave was visible and measurable were necessary for the recording to be taken into account in the analysis. The measurement was manually performed with the aid of a $0.01 \mathrm{~mm}$ precision digital caliper and magnifying lenses, as previously described by other researchers ${ }^{12}$. The beginning and end of the $\mathrm{P}$ wave were defined by the junction between the isoelectric line of the ECG and the initial and final phases of the $\mathrm{P}$ wave. The mean of the sum of three consecutive measurements in the same lead was calculated in all ECG leads (Fig. 2). The longer duration of the $\mathrm{P}$ wave in the ECG was used for analysis. A $P$ wave duration greater than or equal to $110 \mathrm{~ms}$ was considered increased.

\section{Statistical Analysis}

Continuous variables were expressed as mean and standard deviation, while categorical variables were presented as numbers or proportions. KolmogorovSmirnov test was used to test normality. On the other

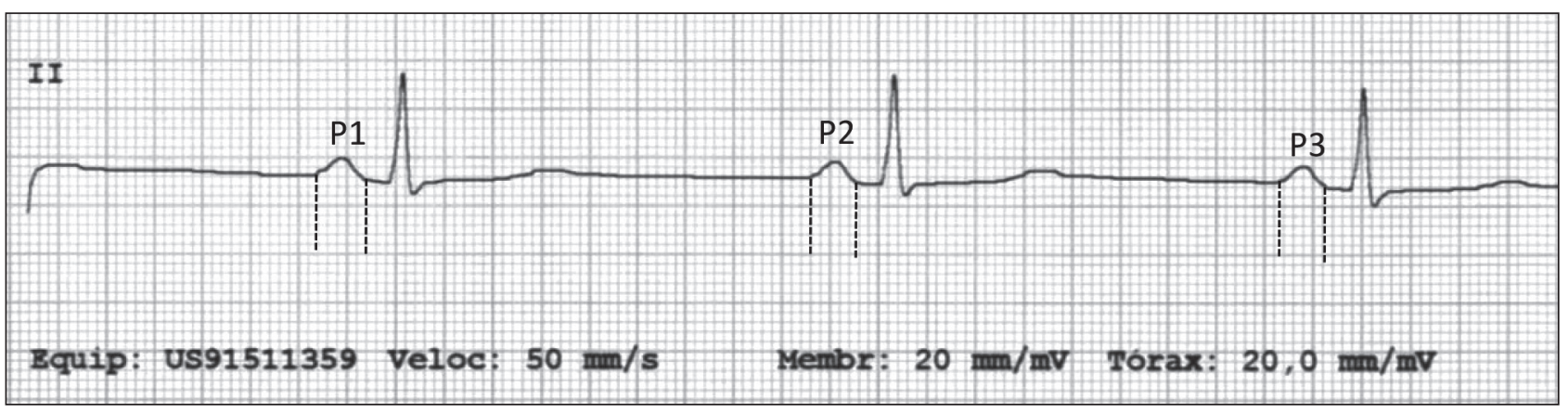

Figure 2. Analysis of the P wave duration in the ECG (lead II). 
hand, to compare continuous variables, paired $\mathrm{T}$ and Wilcoxon tests were used, according to the distribution of the population regarding the normality curve. To evaluate the association between independent variables, a regression model for repeated measurements (Generalized Estimating Equation) was used. Finally, the gamma method was used to test interobserver variability. A p-value below 0.05 was considered statistically significant. The data were analyzed in the $\mathrm{R}$ software version 3.4.1 (R Core Team; Vienna, Austria, 2014).

\section{RESULTS}

In total, 20 patients completed the study protocol (age: $36.35 \pm 10.26$ years, 18 women), 17 performed the gastric bypass technique, and three were submitted to vertical gastrectomy by laparoscopy (see Fig. 1). No postoperative complications were observed among the participants. During follow-up, no clinical complications related to the surgery were observed.
Clinical and laboratory data are shown in Table 1. In the postoperative evaluation, a significant reduction in weight and body mass index (BMI) was observed $(\mathrm{p}<0.001)$. There was a significant improvement in the glycemic and lipidic profile, as well as in the $\mathrm{C}$-reactive protein $(\mathrm{CRP})$ levels $(\mathrm{p}<0.05)$. Creatinine levels remained unchanged.

Measurements of $\mathrm{EF}$ and $\mathrm{P}$ wave duration are shown in Table 2. There was a significant reduction in the EF thickness and in the $\mathrm{P}$ wave duration after bariatric surgery $(7.72 \pm 1.60 \times 4.56 \pm 1.40$ and $109.55 \pm 11.52 \times 98.00 \pm$ $1.49 ; \mathrm{p}<0.001)$, as well as a mean reduction of $11.55 \pm$ $8.49 \mathrm{~ms}$ in the $\mathrm{P}$ wave duration, with a reduction above $10 \mathrm{~ms}$ in 11 study participants ( $55 \%$ of the sample). Before bariatric surgery, eight individuals (40\% of the sample) presented increased P wave duration in ECG ( $\geq 110 \mathrm{~ms}$ ), and only three remained with altered values after bariatric surgery (Fig. 3). In the multiple regression analysis, an association was observed between reductions in the EF thickness and $\mathrm{BMI}$ and reduction in the $\mathrm{P}$ wave duration in the ECG (Table 3).

Table 1. Clinical and laboratory characteristics of the study population.

\begin{tabular}{lccc}
\hline \multicolumn{1}{c}{ Data } & Before bariatric surgery & 12 months after bariatric surgery & p-value \\
\hline Weight $(\mathrm{kg})$ & $126.95 \pm 16.38$ & $89.47 \pm 17.55$ & $<0.001$ \\
Body mass index $\left(\mathrm{kg} / \mathrm{m}^{2}\right)$ & $47.19 \pm 6.15$ & $33.08 \pm 6.91$ & $<0.001$ \\
Systolic blood pressure $(\mathrm{mmHg})$ & $110.10 \pm 12.71$ & $108.50 \pm 7.96$ & 0.224 \\
Diastolic blood pressure $(\mathrm{mmHg})$ & $74.45 \pm 6.80$ & $74.45 \pm 5.25$ & 0.344 \\
Glycemia (mg/dl) & $88.10 \pm 9.30$ & $82.6 \pm 4.36$ & 0.019 \\
Glycated hemoglobin (\%) & $5.45 \pm 0.43$ & $5.18 \pm 0.40$ & 0.003 \\
Total cholesterol (mg/dl) & $184.85 \pm 23.30$ & $151.60 \pm 17.97$ & 0.001 \\
Triglycerides (mg/dl) & $121.10 \pm 50.24 \mathrm{P1}$ & $76.80 \pm 21.33$ & 0.001 \\
C-reactive protein (mg/dl) & $11.79 \pm 7.64$ & $2.63 \pm 2.14$ & 0.001 \\
Creatinine $(\mathrm{mg} / \mathrm{dl})$ & $0.76 \pm 0.13$ & $0.74 \pm 0.14$ & 0.622 \\
\hline
\end{tabular}

Table 2. Data from measurements of $P$ wave duration and echocardiography.

\begin{tabular}{lccc}
\hline \multicolumn{1}{c}{ Data } & Before bariatric surgery & 12 months after bariatric surgery & p-value \\
\hline P wave duration (ms) & $109.55 \pm 11.52$ & $98.00 \pm 10.49$ & 0.001 \\
Left atrial diameter (mm) & $36.12 \pm 3.46$ & $37.06 \pm 2.73$ & 0.40 \\
Left ventricular systolic diameter (mm) & $30.30 \pm 2.49$ & $30.52 \pm 1.51$ & 0.742 \\
Left ventricular diastolic diameter (mm) & $46.20 \pm 4.23$ & $47.70 \pm 2.11$ & 0.137 \\
Left ventricular ejection fraction (\%) & $63.15 \pm 4.25$ & $65.65 \pm 2.85$ & 0.016 \\
Posterior wall (mm) & $9.40 \pm 0.99$ & $9.26 \pm 0.94$ & 0.524 \\
Septum (mm) & $9.45 \pm 1.0$ & $9.61 \pm 0.99$ & 0.606 \\
E/A (cm/s) & $1.31 \pm 0.39$ & $1.60 \pm 0.48$ & $<.001$ \\
Left ventricular mass (g/m $\left.{ }^{2}\right)$ & $151.10 \pm 27.73$ & $158.05 \pm 22.35$ & 0.391 \\
Epicardial fat (mm) & $7.72 \pm 1.60$ & $4.56 \pm 1.40$ & $<0.001$ \\
\hline
\end{tabular}




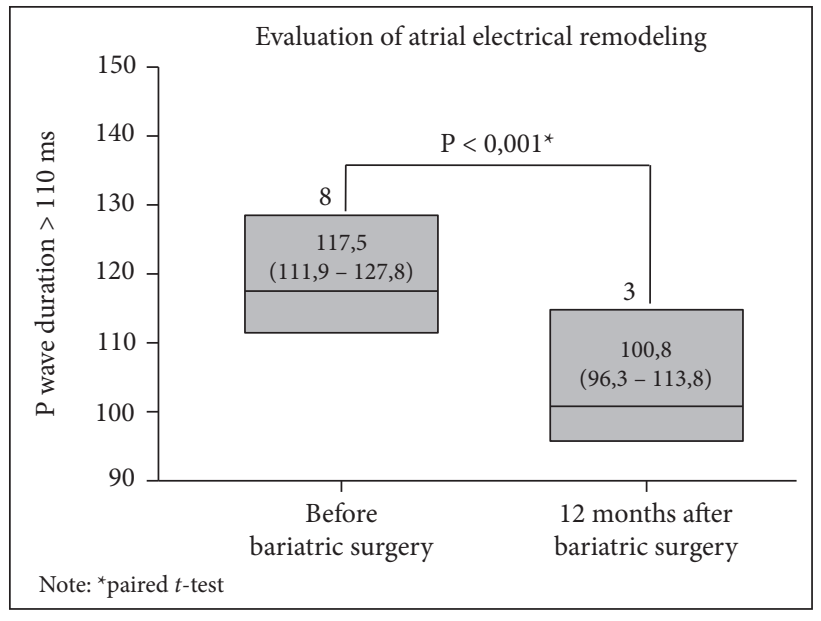

Figure 3. Evaluation of atrial electrical remodeling for obese patients with $\mathrm{P}$ wave duration above $110 \mathrm{~ms}$.

Table 3. Multiple regression analysis.

\begin{tabular}{ccccc}
\hline & & $\boldsymbol{\beta}$ & $\mathbf{D p}$ & $\mathbf{p}$-value \\
\hline $\begin{array}{c}\text { P wave } \\
\text { duration }\end{array}$ & $\begin{array}{c}\text { Epicardial } \\
\text { fat }\end{array}$ & 2.96 & 1.36 & 0.029 \\
& $\begin{array}{c}\text { Body mass } \\
\text { index }\end{array}$ & 0.47 & 0.22 & 0.038 \\
\hline
\end{tabular}

\section{DISCUSSION}

In this study, we observed that $\mathrm{EF}$ reduction promoted by weight loss after bariatric surgery was associated with a significant decrease in the duration of the $\mathrm{P}$ wave. This finding involves cardiac visceral fat in the pathophysiological process of atrial remodeling in morbidly obese patients.

The impact of obesity and EF on the electrical and structural remodeling of atria has been tested in experimental studies. In an animal model, Abed et al. demonstrated that the progressive increase in obesity was able to promote an increase in volume, inflammation, and degree of interstitial fibrosis of the atria, as well as in accumulation of fat in the myocardium and expression of profibrotic atrial receptors ${ }^{13}$. In a study conducted by Lin et al., the incubation of the atrial cell by epicardial adipocytes was able to prolong the action potential, change the functionality of ionic channels and increase the induction of activity triggered when such cell is exposed to the effect of isoproterenol, demonstrating that the visceral fat can modulate the electrophysiological properties of the atrial cell and contribute to the electrical remodeling of the atria ${ }^{14}$. More recently, Mahajan et al. observed that electrophysiological changes in the posterior wall of obese sheep were exclusively attributed to EF infiltration, indicating that this localized phenomenon may contribute to the formation of an arrhythmogenic substrate in the atria ${ }^{15}$.

The association between EF and atrial remodeling is also corroborated by evidence in population records and observational studies. According to the Framingham Heart Study, pericardial fat is associated with electrocardiographic measurements related to atrial conduction ( $\mathrm{P}$ wave duration, $\mathrm{PR}$ interval, and $\mathrm{P}$ wave terminal force) even after adjustments for extracardiac fat deposits ${ }^{16}$. In a population similar to our study, Iacobellis et al. demonstrated a correlation between the dimensions of the left atrium (LA) measured by echocardiography and the EF thickness ${ }^{17}$. In analyses involving ECG and different imaging methods, the $\mathrm{P}$ wave duration was associated with the $\mathrm{EF}$ thickness and volume ${ }^{10-18}$. Together, all these analyses reinforce the hypothesis of cardiac visceral fat involvement in atrial remodeling.

The impact of weight reduction on cardiac remodeling is known and has already been analyzed after bariatric surgery ${ }^{19}$. Observational studies also indicate that weight reduction is capable of promoting a reduction in the duration and dispersion of the $\mathrm{P}$ wave ${ }^{20}$. However, the evidence that indicates the effects of the EF reduction on atrial remodeling is still scarce. In the study conducted by Monno et al., the reverse remodeling of the atria was evaluated in a group of patients submitted to catheter ablation and was inversely associated with greater thickness of $\mathrm{EF}$ and the presence of metabolic syndrome ${ }^{21}$. Although there was no weight reduction during follow-up, a significant reduction in EF was observed in the group that did not present recurrence of atrial fibrillation (AF) after ablation. In our study, the $\mathrm{P}$ wave reduction was associated with a reduction of $\mathrm{BMI}$ and EF. As they are interdependent conditions, the contribution of these variables in models that involve weight and obesity reduction should be considered together, because these variables are hardly dissociated.

Although the measurement of $\mathrm{P}$ wave duration indirectly reflects the size of the atria, and the normalization of this duration has occurred in $40 \%$ of obese patients, in this study we did not observe a reduction in the LA diameter after bariatric surgery. Technical issues related to image acquisition in patients with limited ultrasound window may have interfered with the results and cannot be disregarded. On the other hand, the observed changes may reflect more improvement in conduction than necessarily a reduction 
in the atrial diameter. Evaluations of atrial remodeling by electroanatomic mapping demonstrated that, in areas of low voltage, the presence of fragmented potentials and slowing of atrial conduction were associated with regions of EF deposit in the atria of obese patients ${ }^{22}$. How modifiable are these alterations, due to lifestyle changes and interventions such as bariatric surgery, is a subject for further investigation.

The limitations of this study are mainly related to the size and restrictive nature of the sample. The inclusion of only obese patients without other comorbidities, although it reduces the external validation of the study, was essential to mitigate possible biases of confusion present in analyses involving the evaluation of atrial remodeling and obesity. Currently, the measurement of the EF volume is better estimated by tomography or magnetic resonance imaging, but the availability of these diagnostic methods for morbidly obese patients is limited. Measurement of the $\mathrm{P}$ wave by manually performed ECG may present limited accuracy when compared to other evaluation methods ${ }^{23}$. New studies are necessary to confirm our findings.

\section{CONCLUSIONS}

In a select group of morbidly obese patients submitted to bariatric surgery, the reduction in the $\mathrm{EF}$ thickness was associated with the reduction in the $\mathrm{P}$ wave duration and indicates that cardiac visceral fat and weight reduction may have an important role in the reverse electrical remodeling of the atria.

\section{AUTHOR'S CONTRIBUTION}

Conceptualization, Cardoso AF, Grindler J, Santo MA; Methodology, Cardoso AF, Furtado MS, Fonseca AJ, Pichara NL, Oliveira CR, Cleva R; Investigation, Cardoso AF, Furtado MS, Santo MA; Writing - Original Draft, Cardoso AF, Cleva R, Santo MA; Writing - Review and Editing, Cardoso AF, Santo MA; Supervision, Cardoso AF, Santo MA.

\section{REFERENCES}

1. Iacobellis G, Corradi D, Sharma AM. Epicardial adipose tissue: anatomic, biomolecular and clinical relationships with the heart. Nat Clin Pract Cardiovasc Med 2005 Oct;2(10):536-43. https://doi.org/10.1038/ncpcardio0319

2. Corradi D, Maestri R, Callegari S, Pastori P, Goldoni M, Luong TV, et al. The ventricular epicardial fat is related to the myocardial mass in normal, ischemic and hypertrophic hearts. Cardiovasc Pathol 2004 Nov;13(6):313-6. https://doi. org/10.1016/j.carpath.2004.08.005

3. Sacks HS, Fain JN. Human epicardial fat: what is new and what is missing? Clin Exp Pharmacol Physiol 2011 Dec 1;38(12):879-87. https://doi.org/10.1111/j.14401681.2011.05601.x

4. Cikim AS, Topal E, Harputluoglu M, Keskin L, Zengin Z, Cikim K, et al. Epicardial adipose tissue, hepatic steatosis and obesity. J Endocrinol Invest. Springer International Publishing 2007 Jun;30(6):459-64. https://doi.org/10.1007/ BF03346328

5. Lyon CJ, Law RE, Hsueh WA. Minireview: adiposity, inflammation, and atherogenesis. Endocrinology 2003 Jun;144(6):2195-200. https://doi.org/10.1210/en.2003-0285

6. Eckel RH, Grundy SM, Zimmet PZ. The metabolic syndrome. Lancet 2005 Apr;365(9468):1415-28. htpps://doi. org/10.1016/S0140-6736(05)66378-7
7. Bos D, Vernooij MW, Shahzad R, Kavousi M, Hofman A, van Walsum T, et al. Epicardial fat volume and the risk of atrial fibrillation in the general population free of cardiovascular disease. JACC Cardiovasc Imaging 2017 Nov;10(11):1405-7. https://doi.org/10.1016/j.jcmg.2016.12.005

8. Auer J. Fat: an emerging player in the field of atrial fibrillation. European heart journal 2017;38:62-5. https:// doi.org/10.1093/eurheartj/ehw013

9. Hari KJ, Nguyen TP, Soliman EZ. Relationship between P-wave duration and risk of atrial fibrillation. Expert Rev Cardiovasc Ther2018 Nov;16(11):837-43. https://doi.org/10 $.1080 / 14779072.2018 .1533814$

10. Fernandes-Cardoso A, Santos-Furtado M, Grindler J, Ferreira LA, Andrade JL, Santo MA. Epicardial fat thickness correlates with P-wave duration, left atrial size and decreased left ventricular systolic function in morbid obesity. Nutr Metab Cardiovasc Dis 2017 Aug;27(8):731-8. https://doi. org/10.1016/j.numecd.2017.05.009

11. Iacobellis G, Willens HJ. Echocardiographic epicardial fat: a review of research and clinical applications. J Am Soc Echocardiogr 2009 Dec;22(12):1311-9;1417-8. https://doi. org/10.1016/j.echo.2009.10.013

12. Kosar F, Aksoy Y, Ari F, Keskin L, Sahin I. P Wave duration and dispersion in obese subjects. Ann Noninvas Electro 2008 Jan 1;13(1):3-7. https://doi.org/10.1111/j.1542474X.2007.00194.x 
13. Abed HS, Samuel CS, Lau DH, Kelly DJ, Royce SG, Alasady $M$, et al. Obesity results in progressive atrial structural and electrical remodeling: implications for atrial fibrillation. Heart Rhythm 2013 Jan;10(1):90-100. https://doi.org/10.1016/j. hrthm.2012.08.043

14. Lin YK, Chen YC, Chen JH, Chen SA, Chen YJ. Adipocytes modulate the electrophysiology of atrial myocytes: implications in obesity-induced atrial fibrillation. Basic Res Cardiol2012 Sep;107(5):293. https://doi.org/10.1007/s00395-012-0293-1

15. Mahajan R, Lau DH, Brooks AG, Shipp NJ, Manavis J, Wood JPM, et al. Electrophysiological, electroanatomical, and structural remodeling of the atria as consequences of sustained obesity. J Am Coll Cardiol 2015 Jul 7;66(1):1-11. https://doi.org/10.1016/j. jacc.2015.04.058

16. Friedman DJ, Wang N, Meigs JB, Hoffmann U, Massaro JM, Fox CS, et al. Pericardial fat is associated with atrial conduction: the Framingham Heart Study. J. Am. Heart Assoc 2014 Apr 22;3(2):e000477-7. https://doi.org/10.1161/JAHA.113.000477

17. lacobellis G, Leonetti F, Singh N, Sharma AM. Relationship of epicardial adipose tissue with atrial dimensions and diastolic function in morbidly obese subjects. Int J Cardiol 2007 Feb;115(2):272-3. https://doi.org/10.1016/j.ijcard.2006.04.016

18. Jhuo SJ, Hsieh TJ, Tang WH, Tsai WC, Lee KT, Yen HW, et al. The association of the amount of epicardial fat, P wave duration, and PR interval in electrocardiogram. J Electrocardiol 2018 JulAug;51(4):645-51. https://doi.org/10.1016/j.jelectrocard.2018. 04.009

19. Tuluce K, Kara C, Tuluce SY, Cetin N, Topaloglu C, Bozkaya YT, et al. Early reverse cardiac remodeling effect of laparoscopic sleeve gastrectomy. Obes Surg 2017 Feb;27(2):364-75. https:// doi.org/10.1007/s11695-016-2301-2

20. Falchi AG, Grecchi I, Muggia C, Tinelli C. Weight loss and P wave dispersion: a preliminary study. Obes Res Clin Pract 2014 NovDec;8(6):e614-7. https://doi.org/10.1016/j.orcp.2014.08.005

21. Monno K, Okumura Y, Saito Y, Aizawa Y, Nagashima K, Arai M, et al. Effect of epicardial fat and metabolic syndrome on reverse atrial remodeling after ablation for atrial fibrillation. J Arrhythm 2018 Oct 13;34(6):607-16. https://doi.org/10.1002/joa3.12124

22. Mahajan R, Nelson A, Pathak RK, Middeldorp ME, Wong CX, Twomey DJ, et al. Electroanatomical remodeling of the atria in obesity: impact of adjacent epicardial fat. JACC Clin Electrophisiol 2018 Dec;4(12):1529-40. https://doi. org/10.1016/j.jacep.2018.08.014

23. Dilaveris P, Batchvarov V, Gialafos J, Malik M. Comparison of different methods for manual $P$ wave duration measurement in 12-lead electrocardiograms. Pacing Clin Electrophysiol 1999 Oct;22(10):1532-8. https://doi.org/10.1111/j.1540-8159.1999. tb00358.x 